\title{
SEEDS
}

Surrey Energy Economics

SURREY

Discussion paper Series

ENERGY

ECONOMICS

Centre

\section{Gasoline demand in Greece: \\ the importance of shifts in the underlying energy demand trend}

David C Broadstock and Eleni Papathanasopoulou

March 2013

SEEDS 141
School of Economics University of Surrey 
The Surrey Energy Economics Centre (SEEC) consists of members of the School of Economics who work on energy economics, environmental economics and regulation. The School of Economics has a long-standing tradition of energy economics research from its early origins under the leadership of Professor Colin Robinson. This was consolidated in 1983 when the University established SEEC, with Colin as the Director; to study the economics of energy and energy markets.

SEEC undertakes original energy economics research and since being established it has conducted research across the whole spectrum of energy economics, including the international oil market, North Sea oil \& gas, UK \& international coal, gas privatisation \& regulation, electricity privatisation \& regulation, measurement of efficiency in energy industries, energy \& development, energy demand modelling \& forecasting, and energy \& the environment.

SEEC research output includes SEEDS - Surrey Energy Economic Discussion paper Series (details at www.seec.surrey.ac.uk/Research/SEEDS.htm) as well as a range of other academic papers, books and monographs. SEEC also runs workshops and conferences that bring together academics and practitioners to explore and discuss the important energy issues of the day.

SEEC also attracts a large proportion of the School's PhD students and oversees the MSc in Energy Economics \& Policy. Many students have successfully completed their MSc and/or PhD in energy economics and gone on to very interesting and rewarding careers, both in academia and the energy industry.

Enquiries:

Director of SEEC and Editor of SEEDS:

Lester C Hunt

SEEC,

School of Economics, University of Surrey, Guildford GU2 7XH, UK.

Tel: $\quad$ +44 (0)1483 686956

Fax: $\quad$ +44 (0)1483689548

Email: L.Hunt@surrey.ac.uk

www.seec.surrey.ac.uk 


\title{
Surrey Energy Economics Centre (SEEC) School of Economics University of Surrey
}

\author{
SEEDS 141
}

ISSN 1749-8384

GASOLINE DEMAND IN GREECE:

THE IMPORTANCE OF SHIFTS IN THE UNDERLYING ENERGY DEMAND TREND

David C Broadstock and Eleni Papathanasopoulou

March 2013 


\begin{abstract}
This paper explores the relative importance of factors other than price and income in explaining gasoline demand in Greece between 1978 and 2008. Using a structural time series model (STSM) the long-run elasticities of income and price are 0.45 and -0.32 respectively. Further, it is shown using the estimated underlying energy demand trend (UEDT) that other exogenous factors have been shifting the gasoline demand curve to the right, thus reflecting more energy intensive lifestyles in Greece. Given the results it is contended that the kinds of policies that governments can use to manage gasoline demand and move towards sustainable transportation go beyond the usual price mechanism.
\end{abstract}

Key Words: Motor-gasoline Demand, Sustainable Transportation, Underlying Energy Demand Trend, Household Car Use 


\title{
Gasoline demand in Greece: the importance of shifts in the underlying energy demand trend
}

\author{
David C. Broadstock ${ }^{*}$ and Eleni Papathanasopoulou ${ }^{\#}$
}

\section{Introduction}

One of the primary sectors of the Greek economy is transportation, which as a service is fundamental to all areas of economic development (i.e. economic, societal and environmental). In 2007, this sector accounted for $18 \%$ of Greece's total greenhouse gas emissions (GHG), equating to 24 million tonnes of $\mathrm{CO}_{2}$ equivalent (Eurostat, 2010). Energy consumed for road transport contributed to approximately $80 \%$ of these $\mathrm{CO}_{2}$ emissions helping to sustain the associated negative environmental impacts. ${ }^{1} 63 \%$ of energy used for road transport in Greece is gasoline, the majority of which is used for private car use (Papagianaki and Diakoulaki, 2009) which increased by $71 \%$ between 1990 and 2006 (Papathanasopoulou, 2010).

\footnotetext{
* Research Institute of Economics and Management, Southwestern University of Finance and Economics. 55 Guanghuacun Jie, Chengdu, Sichuan, China, 610074. And Surrey Energy Economics Centre (SEEC), Department of Economics, University of Surrey, Guildford, GU2 7XH, United Kingdom. Email: DavidBroadstock@swufe.edu.cn.

\# Plymouth Marine Laboratory, Prospect Place The Hoe, Plymouth, PL1 3DH, UK. Email: elpa@pml.ac.uk.

${ }^{1}$ The environmental challenges associated with carbon dioxide emissions are well documented by the IPCC with regards to the rising temperature of the earth caused by anthropogenic greenhouse gases, of which carbon dioxide is a major contributor.
} 
At the EU level, transport has been recognised as a key sector to be addressed within the context of achieving international sustainable development targets. The European Commission's 2011 white paper sets a number of goals to be reached by 2050 (European Commission, 2011) with the intention to contribute to a $60 \%$ cut in transport-related GHG emissions. The goals set for transport include for example: eliminating conventionally-fuelled (e.g. gasoline) cars from cities; and a 50\% modal shift from road to rail and water transport for medium and long-distance intercity passenger and freight journeys. Transport and energy-related policies and initiatives will be used to transition towards these targets, and will be based upon economic (financial) and/or non-economic (social, institutional) strategies. In light of the recent global financial crisis and the severity of the resulting financial crisis in Greece, this paper considers the relative importance to consumers of factors other than price and income, which relate in part to the non-economic factors mentioned above.

The economic variables commonly used in describing the demand for gasoline are income and price. It is often the case that results from empirical studies conform to the $a$ priori expectations that increases in income level raise fuel demand while increases in price decrease fuel demand (see Broadstock and Hunt., 2010; Romero-Jordan et al., 2010; Wadud et al., 2008 and Polemis 2006 for some recent examples). In the context of a gasoline demand function, Broadstock and Hunt (2010) demonstrate that factors other than price and income can play an important role in characterizing consumer behavior, in turn implying a possible role for them within fuel/transport policy. Evidence that such factors influence consumer behavior by itself is not innovative. In the context of Greece 
for instance, Koroneos and Nanaki (2007) and Sardianou (2008) have shown that measures of lifestyle and/or social structure can affect modal choice patterns, and by implication energy demand. However, the innovation in Broadstock and Hunt (2010) and as applied here, is to characterize the combined influence of factors other than price and income in the context of pure time-series studies.

The aim of this paper is then to measure the historical significance of factors other than price and income in explaining changes in gasoline demand for Greek transport. Firstly, in Section 2 the empirical demand model and econometric specifications are given. Estimation data and results are presented in Section 3 which also describes how the percentage contributions (to changes in demand) of price, income and 'other exogenous elements' are calculated, while the implications of the results are considered in Section 4 with some reference to the financial crisis. The paper concludes in Section 5.

\section{Econometric specification and approach for estimation}

This section outlines the empirical structure of the demand function to be estimated, and two specific econometric specifications. The empirical time-series demand function is based on a standard log-log specification:

$\ln \left(E_{t}\right)=\alpha+\delta \ln \left(Y_{t}\right)+\beta \ln \left(P_{t}\right)$ 
Where $E_{t}$ is per-capita gasoline consumption in period $t, Y_{t}$ is per-capita real income and $P_{t}$ are real prices, deflated by the all-products consumer price index, with 2005 as the base year. Further description of the data is given in Section 3. The specification given by Equation 1 fails to distinguish between long-run and short-run effects, and also the possibility that other factors, for instance habits, may be important in the demand function. From an econometric perspective this follows from the definition of omitted variable bias, insofar as the exclusion of a variable that should be in a function can cause bias in the model parameters for the variables that were included. Put more simply, in order to ensure unbiased coefficients and hence accurate policy recommendations, it might be important to control for habits and other similar effects.

However habits or other important exogenous variables are sometimes hard or even impossible to measure, particularly for extended time-series. Houthakker and Taylor (1966) proposed that much of this type of information can be summarized into a stock variable, where the current level of gasoline consumption depends upon the combined stock effect resulting from habitual consumption, stock depletion effects, and stock replacement effects. Hunt and Ninomiya (2003) adopt a similar philosophy to the seminal paper of Houthakker and Taylor (1966) in that they assume there are other underlying factors that affect energy demand (termed the underlying energy demand trend or UEDT), but make an important extension insofar as the UEDT allows for current period habits/effects to influence current period demand. The UEDT is captured as a net effect, similar to the unobserved stock model of Houthakker and Taylor (1966). As Williams (1972) highlighted, it is often the case that empirical studies attempt to control for the net 
stock effect rather than estimating the habit/depletion/replacement effects separately, and this is true also for both the UEDT and the unobserved stock approach.

Breunig (2011) suggests that the unobserved stock model, which requires estimation of a moving average error process, was neglected owing to limitations in computer power in the years following the important Houthakker and Taylor (1966) paper. The result of this was to favour standard least-squares estimation of demand functions like Equation (1), and in time the important feature of the moving average error term had been forgotten. In the present paper two alternative models are estimated both aiming to capture long-run and short-run effects, and at the same time control for the effects of non-random unobserved and exogenous variables. Model 1 is based on the more recent empirical approaches to the problem e.g. Hunt and Ninomiya (2003) and more recently Broadstock and Hunt (2010). Model 2 is based on the seminal model structure of Houthakker and Taylor (1966) and more recently Breunig (2011).

In the remainder of this section the specific equations and features of Model 1 and Model 2 will be described, followed by discussion on the approach used for estimation.

\section{Model 1.}

Following Hunt and Ninomiya (2003) and Broadstock and Hunt (2010) among others, the time varying intercept is referred to as an underlying energy demand trend (UEDT). Factors that might influence the intercept are any systematic influences that are not represented within either the direct price of a good or the income level, such as progress 
in technology, social norms, responses to changing policy and other exogenously determined factors. As such, it is plausible to consider that at any given period in time, $t$, where $t=1, \ldots, T$, we can denote the intercept with an additional subscript for time, giving:

$\ln \left(E_{t}\right)=\alpha_{t}+\delta \ln \left(Y_{t}\right)+\beta \ln \left(P_{t}\right)+\theta \ln \left(E_{t-1}\right)+\varepsilon_{t}$

$\alpha=\alpha_{t-1}+\gamma_{t}+\eta_{t}$

$\gamma_{t}=\gamma_{t-1}+\xi_{t}$

Where Equations 2(b) and 2(c) describe how the time-varying constant evolves, in this case a random walk with some drift, but where the drift is also allowed to follow a random walk (this is also referred to as a local linear trend). In order to estimate $\alpha_{t}$ it is possible to use a deterministic approach to specify the term, such as a polynomial trend function. However doing so requires making (potentially arbitrary) assumptions regarding the deterministic structure of the intercept. Moreover, the true function determining the time-varying nature of the intercept may require a complex deterministic approximation consuming valuable degrees of freedom. ${ }^{2}$ To allow for persistent memory/consumer lock in effects Equation 2 is used as a first-order ${ }^{3}$ autoregressive (AR) process. One of the main features of the AR specification is that it allows for short-run

\footnotetext{
${ }^{2}$ For example, if the time varying intercept contains multiple turning points, an additional polynomial term may be required to capture each.

${ }^{3}$ This is restricted to first order on the basis of available observations, given more data it would be preferable to start with a higher order, perhaps 4 years. Also it would be desirable to consider potential distributed lag effects, again the sample size limitations preclude this.
} 
and long-run elasticities to be identified through the partial adjustment mechanism, using income as an example, the short-run elasticity will be $\delta$, while the long-run elasticity becomes $\frac{(\delta)}{(1-\theta)}$ i.e. the long-run multiplier applied to all estimated relationships is $\frac{1}{(1-\theta)}$

To allow for some form of business/macroeconomic cycle in the UEDT the term $\psi_{t}$ is introduced into Equation 2(a), where;

$\psi_{t}=\psi_{0} \cos \lambda_{c} t+\psi_{0}^{*} \sin \lambda_{c} t$

In which $\psi_{0}$ and $\psi_{0}^{*}$ are uncorrelated random variables with zero mean and common variance $\sigma_{\psi}^{2}$. The term $\lambda_{c}$ captures the frequency of oscillation for the cycle. The cycle is considered to be a component of the UEDT, simply one that evolves according to a specific dynamic structure. Equation 2(d) completes the empirical specification for Model 1.

\section{Model 2.}

The model of Houthakker and Taylor (1966) and more recently presented by Breunig (2011) assumes that there is some dynamic 'stock' adjustment, where the discount rate of stock adjustment from one period to the next reflects both physical and psychological aspects of demand, for example vehicle turnover rates and habitual consumption. Breunig 
(2011) demonstrates that if the errors follow a moving average process, which is theoretically plausible, then an appropriate estimating equation to identify the parameters of Equation 2(a) can be written as:

$$
\ln \left(E_{t}\right)=\gamma_{0}+\gamma_{y} \Delta \ln \left(Y_{t}\right)+\gamma_{\Delta y} \Delta \ln \left(Y_{t}\right)+\gamma_{p} \Delta \ln \left(P_{t}\right)+\gamma_{\Delta p} \Delta \ln \left(P_{t}\right)+\theta \ln \left(E_{t-1}\right)+u_{t}
$$

Where $u_{t}$ follows a first order moving average error process or MA(1). After estimation and some derivation it can be seen that the unobserved stock effect, which is effectively equivalent to the time-varying constant term in Equation 2(a) can be calculated as:

$$
S_{t}^{*}=\frac{\ln \left(E_{t+1}\right)-\frac{\hat{\gamma}_{0}}{\left(\hat{\gamma}_{p} / \hat{\gamma}_{\Delta p}\right)}-\hat{\gamma}_{\Delta p} \ln \left(P_{t+1}\right)-\hat{\gamma}_{\Delta y} \ln \left(Y_{t+1}\right)-\varepsilon_{t+1}}{\left[\hat{\gamma}_{v}-1+\frac{\hat{\gamma}_{p}}{\hat{\gamma}_{\Delta p}}\right]}
$$

Noting that this is a retrospective calculation of the unobserved stock/habit effect, the future consumption/price/income data are hence actual and not expectations. The shortrun elasticities are given by $\gamma_{\Delta p}$ and $\gamma_{\Delta y}$ for price and income respectively, while the long-run elasticities for price and income are determined respectively by:

$\frac{\hat{\gamma}_{\Delta p}}{1-\left[\hat{\gamma}_{v}-1+\delta\right]}$ 
$\frac{\hat{\gamma}_{\Delta y}}{1-\left[\hat{\gamma}_{v}-1+\delta\right]}$

\section{Approach for estimation.}

Model 1 and Model 2 are both examples of recursive equations systems. In Model 1 the constant evolves over time as a function of its own history. For Model 2 on the other hand, the error process evolves over time as a function of its own history. Estimation of Model 1 in the empirical literature has been achieved using the structural time series model of Harvey (1989) which allows parameters within a linear equation system to become time-varying within a stochastic recursive system. Estimation is done using a Kalman filter with optimal parameters (given the data and filter specification) obtained using maximum likelihood estimation. For further discussion and a general introduction to the methodology, the reader is referred to Commandeur and Koopman (2007).

Subject to some modifications, the same estimation technique can be directly applied to Model 2. For detail of the modifications required refer to Shumway and Stoffer (2006, p.357), in summary Equation 3 is written as a state space system in which the state transition equation is used to estimate the underlying $\mathrm{AR}(1)$ and $\mathrm{MA}(1)$ terms, while the additional constant, price and income terms are entered directly into an observation equation. Statistically, the Kalman filter is modified to work one step ahead of the filter system used to estimate Equation 2(a), restrictions are also imposed on the variances of the state equation to ensure the errors are the same as those in the observation equation. 
Owing to sample size limitations, the bootstrap algorithm of Stoffer and Walls (1991) will be used to estimate the empirical distributions of the model parameters and for subsequent model assessment. Given that the bootstrap algorithm produces the full empirical distributions, these will be briefly summarized (in Table 1) and plotted (in the Appendix). Formal tests will not be conducted for two reasons; firstly given the full distribution it is quicker and easier to determine confidence in the results visually; secondly, the resulting parameter distributions are highly non-normal and so approximate test statistics are of limited interest. The bootstrap process is replicated 499 times, resulting in 500 total sets of parameter estimates, noting that one additional set of results is added for the standard parametric estimation of the model.

\section{A final note of caution on the interpretation of the UEDT. ${ }^{4}$}

The estimated UEDT is primarily relevant to the historical levels of demand, price and income as observed in the data, and hence the Lucas type critique should be kept in mind. It would be naïve to assume with certainty if given different values for the main variables that the importance (size) of the UEDT would remain unchanged relative to other components in the model. Consider for instance a counterfactual world where the prices were 20 times larger than observed in the data then (i) if demand is assumed unchanged then the UEDT would be larger or (ii) demand would be lower due to the higher price and similarly the UEDT would adjust, this time becoming smaller. Hence the relative size

\footnotetext{
${ }^{4} \mathrm{We}$ are extremely grateful to an anonymous referee for encouraging us to consider this point further. This implies a need to consider more non-linear specifications in future related research. Nonparametric procedures may be an interesting way to embed such non-linearities.
} 
of the UEDT is not independent of the size of other variables. Such scale effects are not strictly excluded from the work presented here. Consider a static demand function rearranged for the UEDT:

$$
\alpha_{t}=\ln \left(E_{t}\right)-\delta \ln \left(Y_{t}\right)-\beta \ln \left(P_{t}\right)
$$

Then $\frac{\partial \alpha_{t}}{\partial P_{t}}=-\beta$ and $\frac{\partial \alpha_{t}}{\partial Y_{t}}=-\delta$, which are not zero. Since $a$-priori $\beta<0$ then $\frac{\partial \alpha_{t}}{\partial P_{t}}>0$ i.e. as price goes up and assuming demand remains unchanged then the UEDT will increase to compensate against the (negative) price response. Nonetheless, future research may still benefit from exploring this issue more directly under alternative functional forms.

\section{Data and Results}

This section first discusses the data used to estimate the empirical energy demand function for Greece, and then presents the results of the econometric modelling. The yearly data, in natural logarithms, are graphed in Fig. 1 over the sample period 19782010, however demand data is only available up until 2008. These data are taken from World Bank and International Energy Agency online databases (2011). The demand data are for per-capita gasoline consumption and illustrate that the trend for gasoline demand in Greece has been increasing at a reasonably constant rate. Prices are measured in terms of regular unleaded gasoline prices for transport, and are deflated using the Greek Consumer Price Index (base=2005). Over the sample period prices were falling consistently at the start of the sample, but began to rise again from the year 2000 . The 2008 oil price volatility and effects of the financial crisis are reflected in the sudden dip 
in prices and subsequent recovery at the end of the sample. Income data is defined as GDP per-capita and is converted to real terms using the GDP deflator (base $=2005$ ). Real per-capita income has been largely in decline over the sample period, though growth was experienced between 2000-2008. The impact of the financial crisis can be seen in declining per-capita income between 2008-2010.

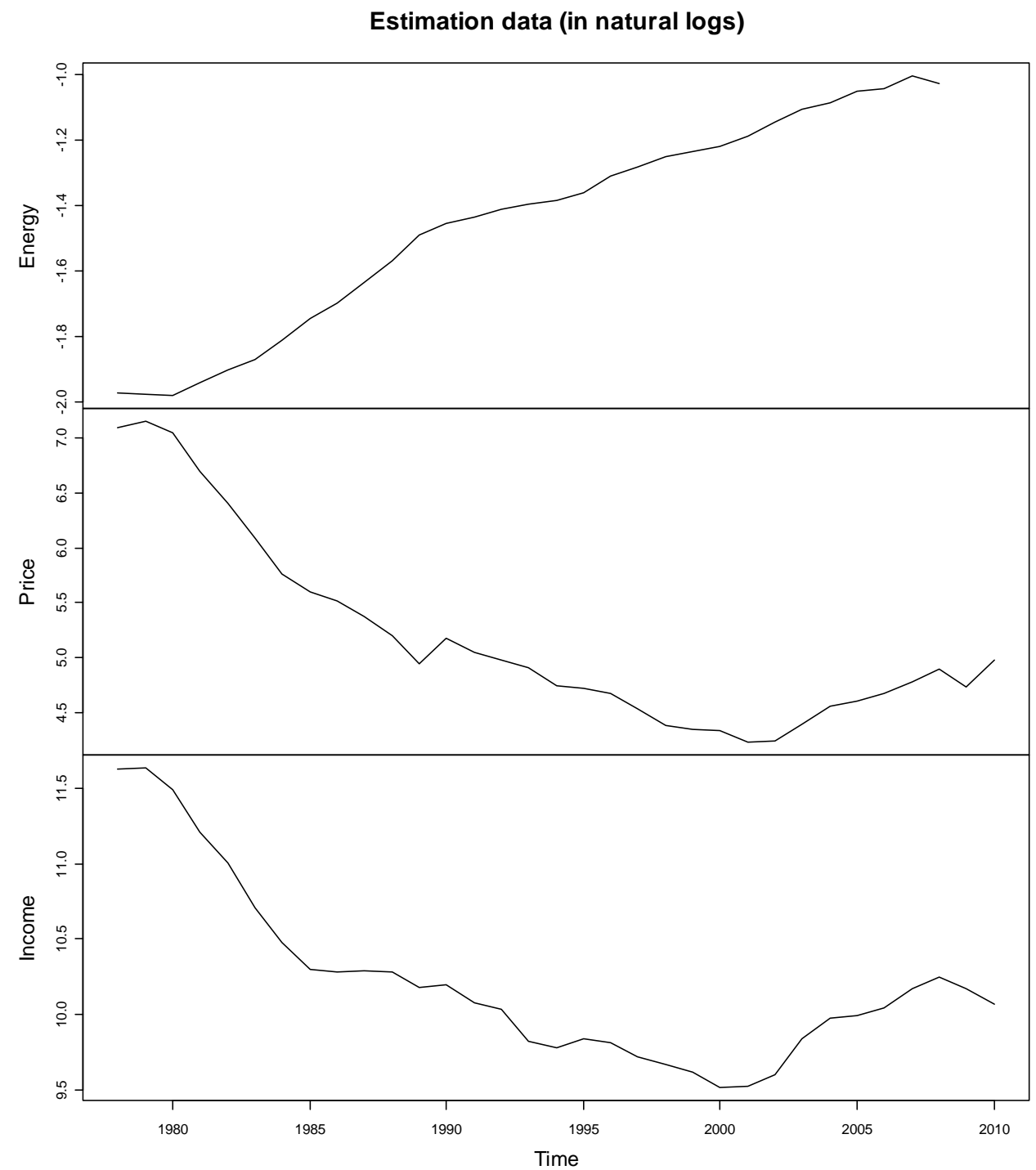

Fig. 1: Gasoline demand, gasoline price and income data for Greece between 1978 and 2010 
The estimation sample only covers 1978-2008 given that demand data are only available up until 2008. Given the financial crisis and an interest to understand whether the crisis had an impact on the elasticites for price and income, the models are estimated for two different subsamples: (a) 1978-2006; (b) 1978-2008. Given some relatively poor performance from early model specifications, Model 1 is also estimated subject to the constraints that $\delta>0$ and $\beta<0$ to ensure the estimated demand function conforms to prior expectations. The estimated elasticities are summarized in Table 1 , where a $*$ is used to denote the models with parameter constraints.

As discussed in the previous section, given the bootstrap estimator, model assessment is a little different than conventional econometric studies. Table 1 therefore summarizes the characteristics of the empirical distribution functions. Model selection is then done on the basis of both short-run and long-run elasticities for price and income conforming to prior expectations, and also with respect to tightness of the short-run parameter confidence intervals. On the basis of these selection criteria, the two best performing models for the full sample are Model 1(b) and Model 2(b), however 1(b) performs much better than 2(b) in terms of plausible confidence intervals. For the restricted sample, 1978-2006, Model $1(\mathrm{a}) *$ is the only model that produces plausible parameter values.

In summary for the restricted sample, the preferred model is Model 1(a)* and for the full sample the preferred model is Model 1(b). It is additionally noted that when considering the long-run elasticities also, the confidence intervals for Model 1(b) are much more satisfactory than for model $1(\mathrm{a})^{*}$ 


\section{i) Elasticities}

Irrespective of sample window, in the short-run the price elasticity of gasoline is estimated at -0.01 suggesting that demand for gasoline is highly inelastic. ${ }^{5}$ This is in contrast to Polemis (2006) who found the short-run price elasticity for gasoline to be 0.10 , although it is noted that this is close to Models 2(a) and 2(b). In the long-run the price elasticity is calculated to be -0.43 prior to the financial crisis and -0.32 after the financial crisis. This would suggest that one consequence of the financial crisis is that consumers have become less elastic in their consumption choices. It is however interesting to note that Model 2(a) and Model 2(b) alternatively suggest that consumers have become more elastic as a result of the financial crisis.

With respect to the income elasticity, in the short-run it is calculated to be 0.01 for both Model 1(a)* and Model 1(b), which is substantially lower than the 0.38 found by Polemis (2006). In the long-run, income elasticites are estimated to be 0.46 for Model 1(a)* and 0.45 for Model 1(b), compared to Polemis (2006) who found that long-run income elasticity was equal to 0.79 . Together, the results for the price and income elasticities suggest much smaller elasticity values than implied by the previous literate. Additionally, the results strongly suggest that the consequence of the financial crisis is to alter the price elasticity of consumers. This is particularly interesting given that income is arguably

\footnotetext{
${ }^{5}$ In attempting to understand why the estimated short-run price elasticities are so low the observed non-linearities in the underlying energy demand trend, though subtle, may partly explain the results. Hitherto used linear trend specifications (for example Polemis (2006)) may fail to adequately capture the dynamics of the trend leading to possible mis-specification bias in the price and income elasticities. It is further noted that the long-run elasticities are much larger, implying that Greek consumers are inelastic in the short-run to changes in price (and income) and take time to adjust to their new equilibrium consumption level.
} 
likely to have been more affected than price, and hence consumers are again arguably selective in the signals they absorb, and the ways in which they respond.

Table 1: Estimation Results (1978-2008)

\begin{tabular}{|c|c|c|c|c|c|c|}
\hline & $\begin{array}{l}\text { Model 1(a) } \\
(1978-2006)\end{array}$ & $\begin{array}{l}\text { Model 1(a)* } \\
(1978-2006)\end{array}$ & $\begin{array}{l}\text { Model 2(a) } \\
(1978-2006)\end{array}$ & $\begin{array}{l}\text { Model 1(b) } \\
(1978-2008)\end{array}$ & $\begin{array}{l}\text { Model 1(b)* } \\
(1978-2008)\end{array}$ & $\begin{array}{l}\text { Model 2(b) } \\
(1978-2008)\end{array}$ \\
\hline \multicolumn{7}{|l|}{ Short-run } \\
\hline \multirow[t]{2}{*}{ Price } & -0.051 & -0.010 & -0.109 & -0.009 & -0.009 & -0.1266 \\
\hline & $(-0.184,0.118)$ & $(-0.029,-0.002)$ & $(-0.251,0.017)$ & $(-0.013,-0.006)$ & $(-0.015,-0.004)$ & $(-0.266,0.015)$ \\
\hline \multirow[t]{2}{*}{ Income } & -0.240 & 0.011 & 0.107 & 0.013 & 0.000 & 0.105 \\
\hline & $(-0.417,0.004)$ & $(0.001,0.028)$ & $(-0.039,0.275)$ & $(0.010,0.015)$ & $(0.000,0.000)$ & $(-0.052,0.274)$ \\
\hline \multirow[t]{2}{*}{$A R(1)$} & 0.620 & 0.976 & 0.667 & 0.972 & 1.055 & 0.629 \\
\hline & $(0.003,1.140)$ & $(0.960,0.996)$ & $(-0.102,1.236)$ & $(0.971,0.973)$ & $(1.054,1.056)$ & $(0.001,1.037)$ \\
\hline \multicolumn{7}{|l|}{ Long-run } \\
\hline \multirow[t]{2}{*}{ Price } & -0.135 & -0.432 & -0.168 & -0.318 & 0.170 & -0.201 \\
\hline & $(-0.483,0.311)$ & $(-1.242,-0.006)$ & $(-0.974,1.101)$ & $(-0.451,-0.197)$ & $(0.068,0.277)$ & $(-1.392,0.252)$ \\
\hline \multirow[t]{2}{*}{ Income } & -0.632 & 0.461 & 0.166 & 0.449 & -0.002 & 0.167 \\
\hline & $(-1.096,0.009)$ & $(0.048,1.207)$ & $(-0.738,0.903)$ & $(0.348,0.513)$ & $(-0.003,-0.000)$ & $(-0.292,1.621)$ \\
\hline \multicolumn{7}{|c|}{ Unobserved stock/habit effects } \\
\hline Average & 2.147 & -0.092 & -1.261 & -0.124 & 0.125 & -6.985 \\
\hline \multicolumn{7}{|l|}{ Average } \\
\hline $\begin{array}{l}\text { growth } \\
\text { Initial }\end{array}$ & -0.001 & -0.005 & -0.015 & -0.006 & -0.019 & -0.003 \\
\hline value & 2.338 & -0.010 & -1.538 & -0.139 & 0.173 & -7.242 \\
\hline Final value & 2.306 & -0.085 & -1.028 & -0.116 & 0.100 & -6.755 \\
\hline
\end{tabular}

Notes:

(i) Values in parentheses are $90 \%$ confidence intervals

(ii) Unobserved stock/habit effects are based on short run equations.

(iii) Given the bootstrap estimation process and the non-normalities it revealed, 90\% confidence intervals are given instead of potentially misleading point estimates (such as a standard error which ignores distributional asymmetries). Notwithstanding this, it remains useful to understand the characteristics of the empirical coefficient distributions, accordingly the Appendix plots these distributions for the main model parameters and hence clearly indicates their clustering around the reported coefficient or otherwise and at the same time avoiding making potentially misleading asymptotic approximations. 


\section{ii) The Underlying Energy Demand Trend (UEDT)}

The UEDT describes the influence that factors other than price and income have upon the demand curve for gasoline. The estimated UEDT for Greece is shown to be increasing with time and is upward sloping, see Fig. 2. Considering this firstly in levels, holding price and income constant, the trend is increasing suggesting that the demand curve is shifting to the right resulting in this category of household activity becoming more energy intensive with time i.e. higher energy consumption levels per unit of income produced. As suggested by Hunt and Ninomiya (2003) there are a number of factors which could explain this increase in intensity:

(i) increased ownership of cars by households;

(ii) the shift from public transportation to private car use due to the perceived time saving and flexibility; and

(iii) the purchase of bigger cars with bigger engines which are subject to worsening congestion situations resulting in additional energy use from inefficient 'stop-start' driving.

The present study does not provide a mechanism for explaining the exact determinants of the UEDT, and for instance the importance of physical effects such as technology relative to psychological effects such as changing preferences. Sardianou (2008) provides some evidence regarding the impact of factors other than price/income on car ownership/use in Greece. Age, marital status, gender, and quality of public transport services are found to be important determinants of car ownership. Surprisingly, the education level of respondents was not significant. The findings of Sardianou (2008) demonstrate that the 
decision to own/use a car in Greece is in part due to factors other than price and income, but importantly, also other than technology. Specifically, changing demographic structure and market structure (e.g. the competitiveness of close substitutes), may at least partly explain changes in the UEDT.

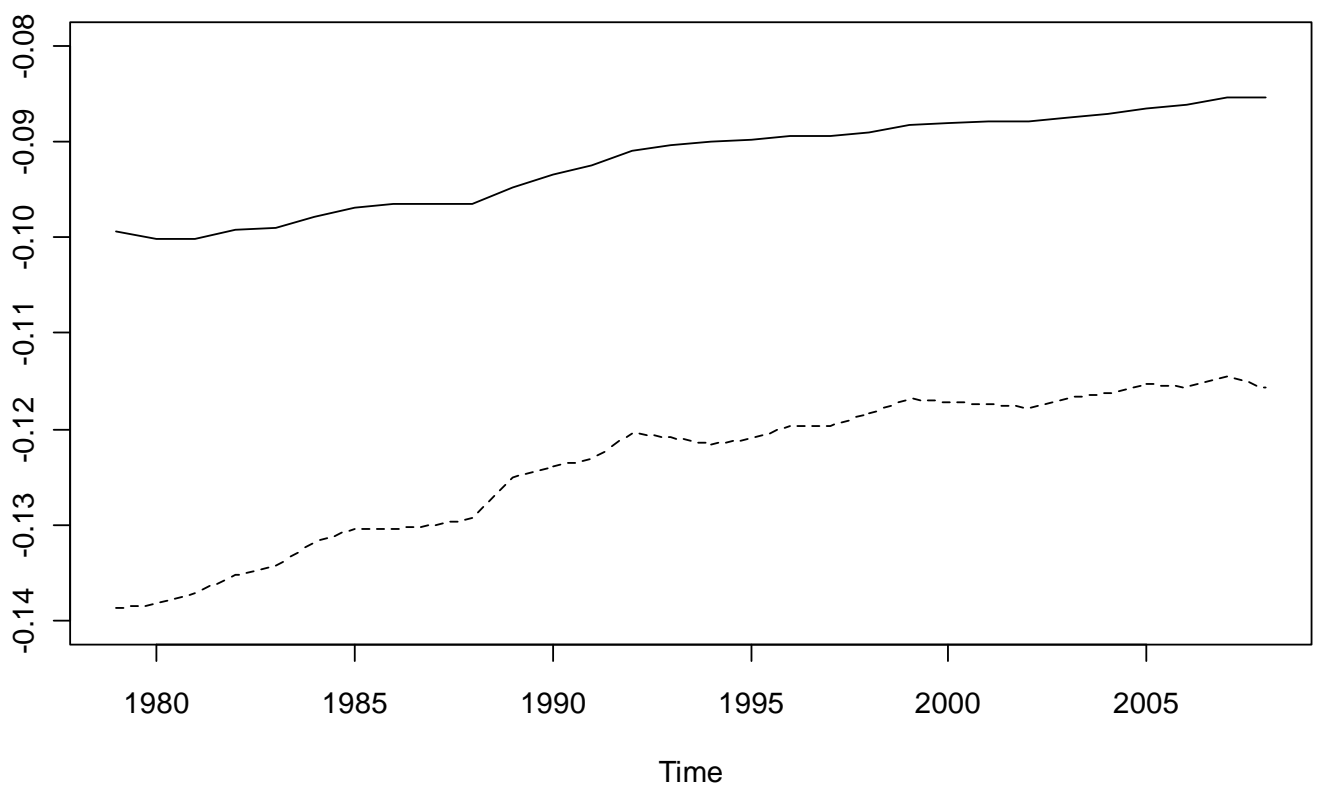

Fig. 2: Underlying Energy Demand Trend, solid line for Model 1(a)* and dotted line for Model 1(b).

The UEDT for Model 1(b) is lower than that of Model 1(a)*, possibly suggesting that one consequence of the financial crisis is for the representative consumer to give less weight to the importance of preferences. Put another way, this would suggest that during the period of crisis, consumers are less likely to be influenced by habit, and their actual consumption choices are more likely to be due to economic factors. 
iii) Contributions of factors other than price and income to changes in gasoline demand over time

The contributions to changes in gasoline demand by the various components of the energy demand function are calculated using the approach devised by Chitnis and Hunt (2009a,b) and Broadstock and Hunt (2010). Given the empirical demand functions of Model 1(a)* and Model 1(b), the changes in energy demand, $\Delta \ln \left(E_{t}\right)$, are made up as the sum of a number of components;

\section{Short-run:}

The contribution from price; $=\beta\left(\Delta \ln \left(P_{t}\right)\right)$

The contribution from income; $=\delta\left(\Delta \ln \left(Y_{t-1}\right)\right)$

The contribution from the UEDT; $=\Delta \mu_{t}+\Delta \psi_{t}$

\section{Long-run:}

The contribution from price; $=\frac{\beta}{1-\theta}\left(\Delta \ln \left(P_{t}\right)\right)$

The contribution from income; $=\frac{\delta}{1-\theta}\left(\Delta \ln \left(Y_{t-1}\right)\right)$

The contribution from the UEDT; $=\Delta \frac{\mu_{t}}{1-\theta}+\Delta \frac{\psi_{t}}{1-\theta}$

Fig. 3 plots the calculated contributions from Model 1(a)* compared to Model 1(b), noting that the long-run contributions are simply scaled versions of the short-run contributions, only the long-run contributions are shown. With the exception of the first 
year of the sample for Model $1(\mathrm{a})^{*}$, the two plots are qualitatively similar. The most probable cause of the difference in values for the first year is that the parameter constrained model suffers a greater level of start-up irregularity in the Kalman filter.

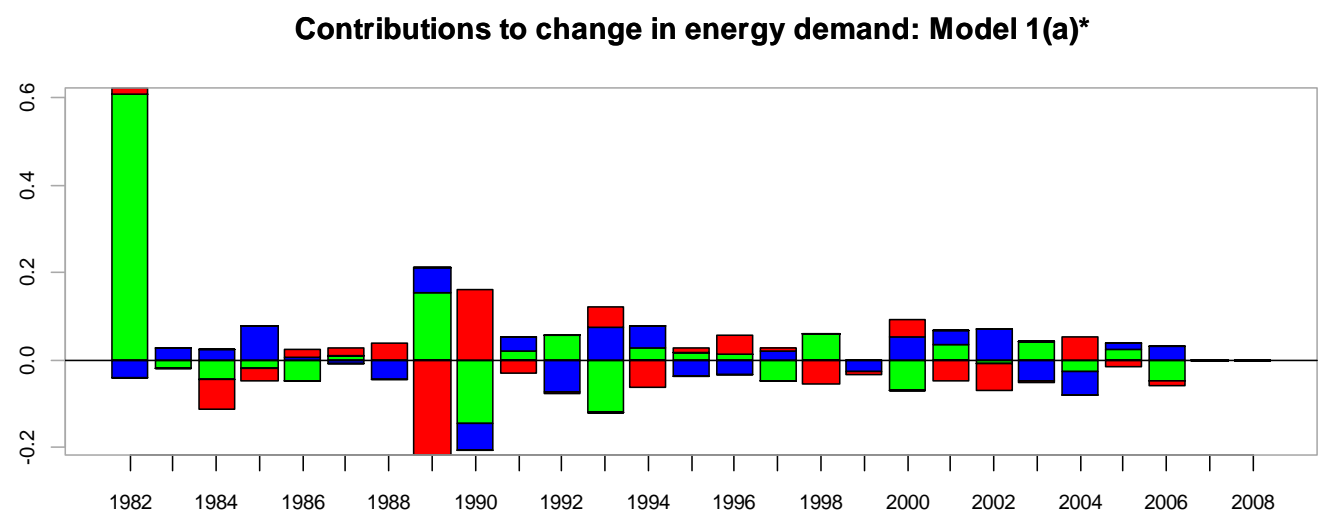

Contributions to change in energy demand: Model 1(b)



Fig. 3: Contribution of price, income and other exogenous elements (UEDT) in the changing demand for gasoline $($ green $=$ UEDT, blue $=$ income, red $=$ price $)$

In terms of contributions towards changes in energy demand, there is no clear trend for price, income or other exogenous effects. However, it can be seen clearly that the contribution of the UEDT is roughly equal to the sum of the combined economic 
contributions (e.g. price and income) in most periods. This behavior is maintained for $2007 / 2008$, with no evidence that the financial crisis has diminished the relative influence of exogenous factors upon changes in gasoline consumption. Changes over time are clearly not driven by only prices and income. Since it is not possible to identify what these other factors are, this remains an open research question. However, there may be scope for travel demand management strategies that use factors other than price and income.

\section{Implications of the results on transport policy in Greece}

Given the results of the econometric model in the previous section, this section considers policy from two perspectives. Firstly, the section considers the general implications for Greek transport policy; secondly, observations are made in the context of the financial crisis. Given the on-going nature of the financial crisis, this latter discussion is deliberately limited. The focus of this paper is retrospective, and at no point aims to make projections on the future, regardless it would be remiss not to consider how the crisis may influence either the stability or validity of the results/conclusions.

Through the Kyoto Protocol Greece committed to ensuring that its GHG emissions between 2008 and 2012 would not exceed more than 25\% increase of its 1990 levels. Based on recent national inventory reports (Ministry of Environment, Energy and Climate Change, 2010) submitted to the office of the UN's Framework Convention on Climate Change, Greece showed that in 2008 its GHG emissions had increased by 
approximately $23 \%$. Of this total $86.5 \%$ was carbon dioxide which in itself had increased by $32.4 \%$. The report further stated that $21.8 \%$ of carbon dioxide emissions are due to transport activity dominated by car use. Put another way, by 2008, Greece was meeting Kyoto targets, but only just, and given the growth in transport demand and gasoline consumption, could possibly exceed their target before 2012 .

Faced with the challenge of needing to curtail growth in emissions, the Greek government (Ministry of Infrastructure, Transport and Networks, 2010) recently proposed a number of strategies to reduce carbon dioxide emissions attributable to the transportation of people. Taking each of these four strategies in turn; the first is to commission further research into ways of replacing the existing stock of passenger vehicles with more environmentally friendly vehicles. Second is to promote the construction of large scale bicycle routes - one within Athens $(13 \mathrm{~km})$ and the second connecting Athens' city centre with the coast $(8 \mathrm{~km})$. Third, to increase the number of public transport vehicles powered by alternative fuel sources, e.g. hybrid and hydrogen fuel cell buses. Lastly, Greece hopes to promote eco-driving amongst private car owners.

Although there is little information as to how these strategies will be/are being implemented, the mere existence of these strategies, particularly the first and fourth of these, is a stated acknowledgement of belief that factors other than price and income can form part of travel demand management strategies. This might be considered as being consistent with the econometric results in this paper. More specifically, the paper has taken a data/model based approach to exemplify the importance of factors other than 
price and income in consumer demand choices, and shown that their effect is more than trivial. The first strategy is a technological response (in the service of road transport), while the fourth is aimed at behavioural change of drivers, neither of which affect income levels, or the price of the fuel directly, hence they fall into the category of factors other than price and income.

Turning attention to the nature of the Greek economy in recent years, the financial crisis presents a daunting social and political landscape for Greece, at least for the next few years. Already there is evidence that related policy is adjusting to further complement pricing based instruments with other demand shifting factors, as discussed above. How long the crisis will last is difficult to predict, but irrespective it is not hard to appreciate that consumers tend not to like price rises. From a behavioural perspective, this suggests that the value of trying to regulate consumer demand using non-price instruments will not wane. Put another way, the conclusion that factors other than price and income can be an effective part of the policy repertoire of the central planner, is not a conclusion that is likely to change. The relative importance may fluctuate, possibly with the economic factors becoming more relevant when sustained growth resumes.

\section{Conclusions}

This paper estimated two alternative models aiming to describe the role and importance of factors other than price and income in the demand for gasoline in Greece. Using data 
on the demand for gasoline for road transport in Greece, it was shown that there is a potentially important role for using policy interventions that go beyond the usual price controls to manage gasoline consumption. The model of Houthakker and Taylor (1966) and more recently Breunig (2011) compared well to the alternative model specification (the structural time series model) used for instance recently by Broadstock and Hunt (2010), though does not turn out to be the preferred specification.

It has already been recognized by the Greek government that changes in gasoline demand can be influenced through the provision of services which cater to the non-price/income determined elements of consumer behavior. This was seen for instance in strategies to renew the vehicle stock, provide bicycle lanes, provide green public transportation and educate drivers in eco-driving. Unfortunately, the financial crisis may have hindered the implementation of these plans in certain instances, but may also have provided a unique opportunity for non-price based policy strategies to become core elements of central government's planning. The financial crises will certainly have a continued impact on consumer demand that simply is not yet sufficiently reflected in currently available data, and as more data becomes available it will be necessary to review the Greek situation.

It has been assumed throughout that it is possible for the UEDT to be shifted. The only case in which this would not be valid is if the UEDT was effectively randomly determined, but at the very least this term should embed energy efficiency and technological improvements, hence the assumption is not implausible. Further research is required into the elements that shift the underlying energy demand trend. More 
specifically, greater efforts are needed to identify specific policies that governments can use beyond the usual price mechanism. Such research would likely need to draw upon household level data, controlled experiments or a combination of the two. In undertaking future studies there are several other features that may also be interesting to consider, such as potential price endogeneity and the need to estimate supply and demand simultaneously. The role of inter-fuel substitution will become increasingly more important in transportation fuel demand studies as peak-oil concerns continue to grow, and research needs to consider how to cater for this in empirical models. It may also be interesting to consider the importance of price-stability compared to an alternative regime of price-instability. 


\section{References}

Breunig, R. 2011. Should single-equation dynamic gasoline demand models include moving average terms? Journal of Transportation Research, Part D, 16(6):474-477.

Broadstock D. C. and Hunt L. C. 2010. Quantifying the impact of exogenousnoneconomic factors on UK transport oil demand. Energy Policy 38:1559-1565.

Chitnis, M. and Hunt, L.C. 2009a. Modelling UK Household Expenditure: Economic Versus Non-economic Drivers. RESOLVE Working Paper Series, 07-09, University of Surrey.

Chitnis, M. and Hunt, L.C. 2009b. What Drives the Change in UK Household Energy Expenditure and Associated CO2 Emissions, Economic or Non-economic Factors? RESOLVE Working Paper Series, 08-09, University of Surrey.

Commandeur, J. J. F. and Koopman, S. J. 2007. An introduction to State Space Time Series Analysis, Oxford University Press, Oxford, UK

Dimitropoulos J., Hunt L.C. and Judge G. 2005. Estimating underlying energy demand trends using UK annual data. Applied Economic Letters, 12: 239-244.

European Commission. 2011. White Paper: Roadmap to a Single European Transport Area - Towards a competitive and resource efficient transport system. Available at: http://ec.europa.eu/transport/strategies/2011_white paper_en.htm. (Last accessed November 2011).

Eurostat. 2010. Eurostat's Environmental Database. Available at www.epp.eurostat.ec.europa.eu (Last accessed June 2010).

Houthakker, H. S. and Taylor, L. D. 1966. Consumer Demand in the United States: Analyses and Projections 1929-1970, Cambridge University Press, Cambridge, MA, USA.

Hunt, L. C. and Ninomiya, Y. 2003. Unravelling trends and seasonality: A structural time series analysis of transport oil demand in the UK and Japan. The Energy Journal, 24, 63-96.

International Energy Agency. 2010. Data Services accessible from www.iea.org. 
Koroneos, C. and Nanaki E. 2007. Environmental assessment of the Greek transport sector. Energy Policy 35:5422-5432.

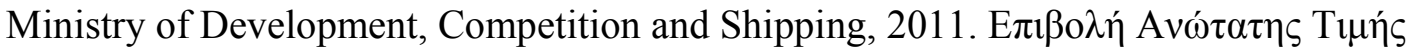

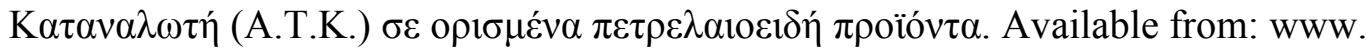
http://www.mindev.gov.gr. (Last accessed November 2011).

Ministry of Environment, Energy and Climate Change, 2010. National Inventory Report. Available from: www.unfccc.org. (Last accessed November 2011).

Ministry of Infrastructure, Transport and Networks. 2010. Committee for Green Transport. Available from: www.yme.gr. (Last accessed November 2011).

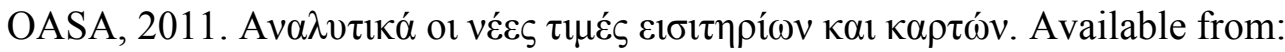
www.oasa.gr (Last accessed November 2011).

Papathanasopoulou E. 2010. Household consumption, associated fossil fuel demand and carbon dioxide emissions: the case of Greece between 1990 and 2006. Energy Policy 38:4152-4162.

Polemis M. L. 2006. Empirical assessment of the determinants of road energy demand in Greece. Energy Economics 28:385-403.

Romero-Jordán, D., del Río P., Jorge-García M. and Burguillo M. 2010. Price and income elasticities of demand for passenger transport fuels in Spain: Implications for public policies. Energy Policy 38:3898-3909.

Sardianou E. 2008. Estimating space heating determinants: An analysis of Greek households. Energy and Buildings, Volume 40(6):1084-1093.

Shumway, R. H. and Stoffer, D. S. 2006. Time Series Analysis and Its Applications With R Examples, Springer, USA.

Stoffer, D. S. and Walls, K. D. 1991. Bootstrapping State-Space Modeles: Gaussian Maximum Likelihood Estimation and the Kalman Filter, Journal of the American Statistical Association, 86(416):1024-1033.

Wadud, Z., Noland R. B, Graham D.J. 2008. Equity analysis of personal tradable carbon permits for the road transport sector. Environmental Science and Policy, 11:533533. 
Appendix: Empirical Coefficient distributions.
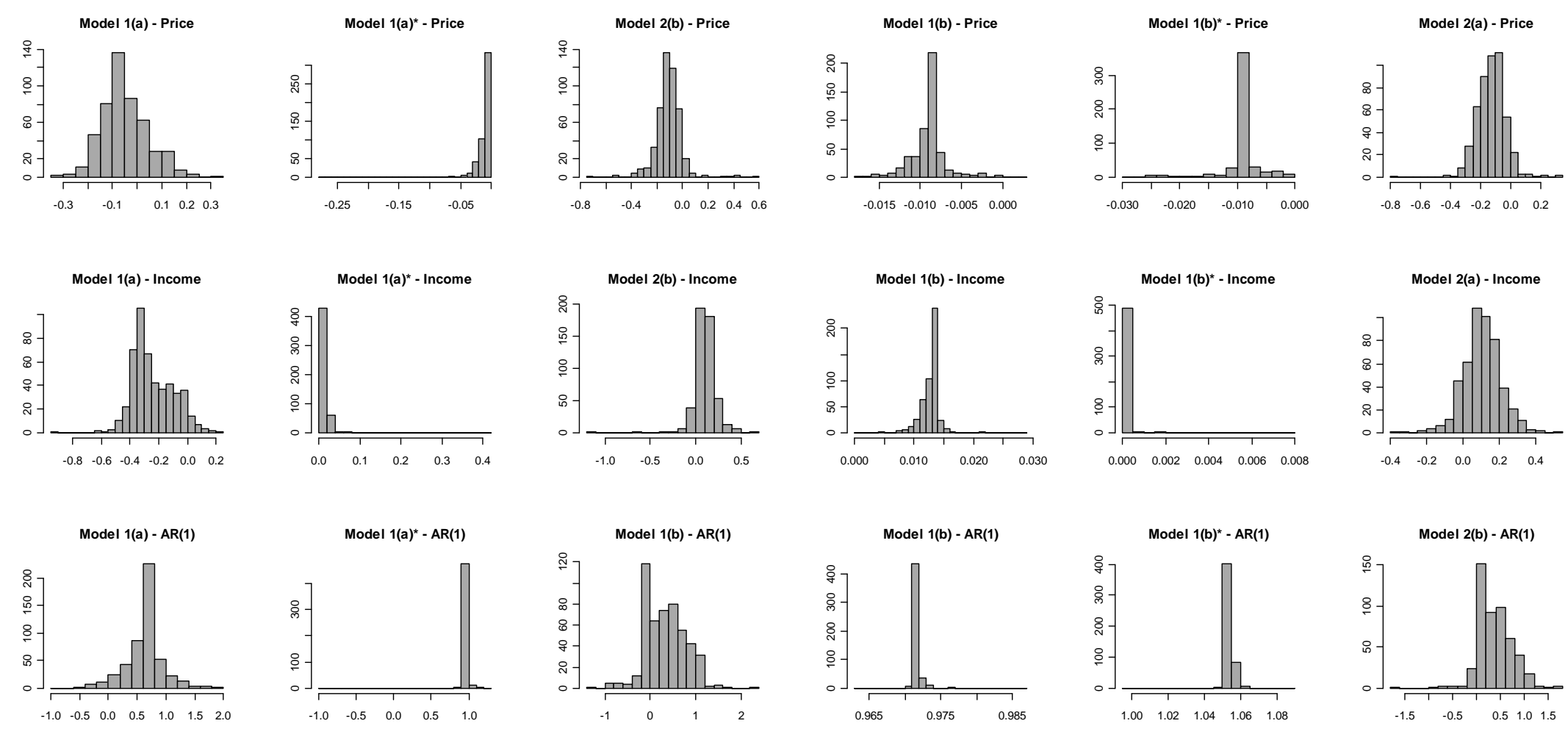

Fig. A1: Histograms of the empirical, or bootstrap, distributions of the price, income and lag adjustment terms from the estimated models. The $x$-axis denotes the coefficient value, while the $y$-axis denotes the frequency within each of the 20 bins. Each distribution is formed from 499 bootstrap replications. 
Fig. A1 plots the empirical distributions for the price, income and lag adjustment terms from each of the models. These are formed from the 499 bootstrap replications. The distributions are clearly non-normal and in many cases include a number of extreme values which strongly influence calculated values such as the mean or standard deviation of a distribution, but generally speaking the empirical distributions have a peak which is quite discernible from the remainder of the distribution. Though not presented, it is noted that similar patterns hold for the long-run price and income elasticities. 
Note:

This paper may not be quoted or reproduced without permission

Surrey Energy Economics Centre (SEEC) School of Economics

University of Surrey

Guildford

Surrey GU2 7XH 
SuRReY

ENERGY $_{\text {Net }}$

Economics

Discussion PAPER

$\mathbf{S}_{\text {ERIES }}$

\title{
For further information about SEEC please go to:
}

\author{
www.seec.surrey.ac.uk
}

